\title{
DEVELOPMENT OF AUTOMOBILE GASKETS FROM LOCAL FIBRES
}

\author{
I.O. Oladele and B.O. Adewuyi \\ Dept of Metallurgical and Materials Engineering, \\ Federal University of Technology, Akure, Nigeria
}

\begin{abstract}
Homogenized pastes were prepared by adding top-bond white glue as binder to natural fibrous material prepared out of different proportions of bamboo (Ozizentera arbonica), coconut husk (Cocus nucifera), sponge (Acanthus montanus) and wood (cordial). Test samples were prepared from dried cast samples for creep and hardness tests. The results of the analysis were used to determine the material that has close properties to the commercially sourced gasket used as control. The overall assessment of the compatibility and suitability tests confirmed the possible applicability of the materials as gasket in fuel pump, carburetors and in engine oil pumps. The locally produced materials have been tested and found suitable as substitute to the conventional material in this order: Coconut husk mixed with sponge $(\mathrm{Ch}+\mathrm{Sp})$ in uniform proportion; Coconut husk (Ch) alone without any mixture, and the mixture of the four fibres $(B a+C h+S p+W d)$.
\end{abstract}

Keywords: Gasket, Agricultural woody fibres, Creep and Hardness.

\section{INTRODUCTION}

In petroleum, automobile, oil and gas industries and other industries where mechanical parts are fitted together gaskets are commonly used. Gasket is a specific form of mechanical seal used to fill space in order to keep liquids, gases and other contaminants from getting to where they are not wanted. Gaskets can come in all shapes and sizes and have a variety of materials to choose from; each design to perform sealing functions for specific purposes (Martin et al., 1985; Duffy, 1998). Designers of machines, vehicles, and structures must achieve acceptable levels of performance and economy, while at the same time striving to guarantee that the item is both safe and durable (Adewuyi, 1999; Akanya, 2006). The studies of the mechanical behaviour of materials such as automobile gaskets is therefore necessary to assure performance, safety, and durability and also to avoid excess deformation, that is, bending, twisting, or stretching, of the component parts of the engineering system during service (Dowling, 1993). The fabrication and properties of composites are strongly influenced by the proportions and properties of the matrix and the reinforcement (Dieter, 1988). The most 
basic concern in design to avoid structural failures is that the stress in a component must not exceed the strength of the material. Since creep rate is a design parameter that gives the rate at which the material is deformed, the creep rates as well as the hardness properties of the produced gaskets were compared with those of the commercially sourced gasket to ascertain the suitability of the gaskets produced. Advanced or high-performance materials are critical for any of the modern industrial applications. It is generally true that progress in any field (energy, building materials, transportation, consumer product etc.) depends mainly on the availability of suitable materials having specific characteristics. In this regard, technological development depends on advances in the field of materials and the final limitation on such advancement depends on availability of materials (Brandt et al., 1989). Designing materials for specific applications is indeed the underlying philosophy of composite materials such as gaskets. The materials marketplace is increasingly becoming a highly competitive arena where substitution of traditional imported materials by locally produced engineering materials is now the norm (Evans, 2003). These coupled with the high cost of synthetic fibres had necessitated the use of natural fibers for this work. However, quality and value added to such materials as well as the energy cost are critical in the final cost (Chawla, 1993; Chris, 2006). The work also involved evaluating the relevant mechanical properties such as creep rate and hardness and determines the suitability of the product as a material for automobile gaskets when it comes in contact with different media such as petroleum product. One of the difficulties in using local fibrous materials is getting a suitable binder that will not adversely affect the performance during service. Adewuyi (1999) had shown the effect of binders on the mechanical properties of locally produced mineral fibres. Similarly, Agarwal and Broutman (1990) discussed analysis and performance of fibre composites. In Nigeria, presently gasket are only imported and not produced locally. Hence this research is an effort to use locally available agricultural plant materials to produce gaskets.

\section{MATERIALS AND METHODS}

Natural fibers (bamboo, coconut husk, sponges and wood) were sun dried and pulverized in a ball mill and sieved with a sieve aperture size of $850 \mu \mathrm{m}$. Fifteen different compositions were obtained and homogeneous pastes were produced by mixing the pulverized fibres with Top Bond white glue (Table 1). The first set of four sample

Table 1 Materials Composition and Proportions

\begin{tabular}{lll}
\hline Materials & Fibre Composition (\%) & Proportion (\%) \\
\hline $\mathrm{Ba}$ & Bamboo & 100 \\
$\mathrm{Ch}$ & Coconut husk & 100 \\
$\mathrm{Sp}$ & Sponges & 100 \\
$\mathrm{Wd}$ & Wood & 100 \\
$\mathrm{Ba}+\mathrm{Ch}$ & Bamboo and Coconut husk & $50: 50$ \\
$\mathrm{Ba}+\mathrm{Sp}$ & Bamboo and Sponges & $50: 50$ \\
$\mathrm{Ba}+\mathrm{Wd}$ & Bamboo and Wood & $50: 50$ \\
$\mathrm{Ch}+\mathrm{Sp}$ & Coconut husk and Sponges & $50: 50$ \\
$\mathrm{Ch}+\mathrm{Wd}$ & Coconut husk and Wood & $50: 50$ \\
$\mathrm{Wd}+\mathrm{Sp}$ & Wood and Sponges & $50: 50$ \\
$\mathrm{Ba}+\mathrm{Ch}+\mathrm{Sp}$ & Bamboo,Coconuthusk and sponges & $33.3: 33.3: 33.3$ \\
$\mathrm{Ba}+\mathrm{Ch}+\mathrm{Wd}$ & Bamboo,Coconuthusk and Wood & $33.3: 33.3: 33.3$ \\
$\mathrm{Ba}+\mathrm{Sp}+\mathrm{Wd}$ & Bamboo,Sponges and Wood & $33.3: 33.3: 33.3$ \\
$\mathrm{Ch}+\mathrm{Sp}+\mathrm{Wd}$ & Coconuthusk,Sponges and Wood & $33.3: 33.3: 33.3$ \\
$\mathrm{Ba}+\mathrm{Ch}+\mathrm{Sp}+\mathrm{Wd}$ & Bamboo,Coconuthusk,Sponges and Wood & $25: 25: 25: 25$ \\
\hline
\end{tabular}

Journal of Science and Technology, Vol. 28, No. 3, Dec., 2008153 
were made from each of the fibres (100\%); the next set of six samples were produced by combining two fibres together at equal proportions $(50 \%)$; then another set of four samples were produced by combining three of the fibres together at equal proportions and finally, production of samples made by the combination of the entire four woody fibres. The ratio of fibres to matrix used was 40:60 measured with volumetric measuring cylinder in millilitres.

From these various compositions, gasket sheets for creep and hardness tests were produced by pouring the paste into a prepared mould made from plywood (dimension $105 \mathrm{~mm} \times 115 \mathrm{~mm} \mathrm{x}$ $3 \mathrm{~mm})$ to give the test specimens the desired thickness and shape. The moulds after pouring were compressed by placing a weight of $50 \mathrm{~kg}$ for five minutes on them. After solidification, the casts were removed and air dried. Creep and hardness tests samples were cut from the gasket sheets.

\section{Creep Test}

Creep test was carried out using Laboratory SM106 Creep Measurement Apparatus. Stop watch was used to record the time interval for the extension produced by the applied load on the specimens. The specimen was positioned on the machine while a constant, predetermined load of $0.2 \mathrm{~kg}$ was added and the load hanger was raised to the loading position and fixed at that point. The load was gently released and the stop watch engaged. Extension readings from the measuring instrument were taken after every one minute for 60 minutes.

\section{Hardness Test}

Tests were carried out at ambient and at elevated temperatures using Equip Tip Hardness Tester. At ambient temperature, the materials were placed horizontally on the platform and the indenter was pressed five times for indentation on each of the sample. To measure the hardness at an elevated temperature, the materials were placed into the furnace and maintained at an elevated temperature of $200^{\circ} \mathrm{C}$ for 30 minutes.
After removing the samples from the furnace the same procedure was used for the hardness measurement. Hardness values were shown on the screen corresponding to Brinell hardness number.

\section{Suitability Test}

Suitability test was carried out on the selected materials using water, engine oil and petrol. The materials maintained their respective structures in engine oil and petrol whereas it softens in water.

\section{RESULTS AND DISCUSSION}

In an engine where machined parts fit together, it is very difficult to machine metal parts to the degree of accuracy necessary for leak proof joints. As the engine expands and contracts during warm up and cooling periods, there are minute shifts in the fastened parts. This, coupled with vibration, will loosen many parts to the point of leakage. Gasket material is somewhat resilient (soft and springy) and will adapt itself to expansion and contraction. It will also conform to irregularities in the surface of the mating parts (Martin et al., 1985)

Results from the creep tests are shown in Table 2 , while the results of hardness are shown in Figures 1-4. From the results in Table 2, the mixtures of sponge and wood fibres gave the highest density value. However, gasket materials produced from coconut husk and mixtures of coconut husk with other fibres gave the lowest values of creep rate, closer to the commercially sourced gasket material used as the control. Creep rate is a design parameter that gives the rate at which the material is deformed. High creep rate means early deformation and consequent failure while low rate means prolonged deformation and failure (Hearns, 1997). Creep rate of $0.035 \mathrm{~mm} / \mathrm{min}$ is good for application in an area where gasket material that is somewhat resilient (soft and springy) and will adapt to expansion and contraction (Martin et al., 1985). Rupture time is the period at which a material experience major changes in its microstructure 
Table 2: Average Values for the Density, Creep Rate and Hardness Measurement

\begin{tabular}{|c|c|c|c|c|c|}
\hline Materials & $\begin{array}{c}\text { Density } \\
\text { G/ml }\end{array}$ & $\begin{array}{l}\text { Creep } \\
\text { Rate } \\
\mathrm{mm} / \mathbf{m i n} \\
\mathbf{0 . 2 0 0 0}\end{array}$ & $\begin{array}{c}\text { Hardness } \\
\text { Rm. Temp } \\
\text { (BHN) } \\
86\end{array}$ & $\begin{array}{c}\text { Hardness } \\
\text { Elev. Temp. } \\
\text { (BHN) } \\
91\end{array}$ & $\begin{array}{l}\text { Remarks } \\
\text { Overall assessment } \\
\text { Poor }\end{array}$ \\
\hline $\mathrm{Ch}$ & 0.882 & 0.02857 & 161 & 178 & Good creep rate \\
\hline $\mathrm{Sp}$ & 1.074 & 0.1500 & 159 & 148 & Good Density \\
\hline Wd & 0.884 & 0.1000 & 133 & 160 & Good Hardness \\
\hline $\mathrm{Ba}+\mathrm{ch}$ & 0.921 & 0.3333 & 153 & 182 & Good density \& hardness \\
\hline $\mathrm{Ba}+\mathrm{Sp}$ & 0.959 & 0.0500 & 148 & 101 & Good density \\
\hline $\mathrm{Ba}+\mathrm{Wd}$ & 0.876 & 0.1750 & 161 & 126 & Poor \\
\hline $\mathrm{Ch}+\mathrm{Sp}$ & 0.921 & 0.02222 & 176 & 164 & Good creep rate \\
\hline $\mathrm{Ch}+\mathrm{Wd}$ & 0.780 & 0.0300 & 164 & 108 & Good creep rate \\
\hline $\mathrm{Sp}+\mathrm{Wd}$ & 1.121 & 0.0400 & 157 & 103 & Good density \\
\hline $\mathrm{Ba}+\mathrm{Ch}+\mathrm{Sp}$ & 0.925 & 0.0500 & 162 & 155 & Moderate \\
\hline $\mathrm{Ba}+\mathrm{Ch}+\mathrm{Wd}$ & 0.887 & 0.0499 & 120 & 153 & Moderate \\
\hline $\mathrm{Ba}+\mathrm{Sp}+\mathrm{Wd}$ & 1.000 & 0.05714 & 163 & 145 & Moderate \\
\hline $\mathrm{Ch}+\mathrm{Sp}+\mathrm{Wd}$ & 1.052 & 0.03125 & 101 & 109 & Good creep rate \\
\hline $\mathrm{Ba}+\mathrm{Ch}+\mathrm{Sp}+\mathrm{Wd}$ & 0.938 & 0.03333 & 194 & 155 & Good creep rate \\
\hline Control & 1.744 & 0.00625 & 203 & 210 & Good creep rate \\
\hline
\end{tabular}

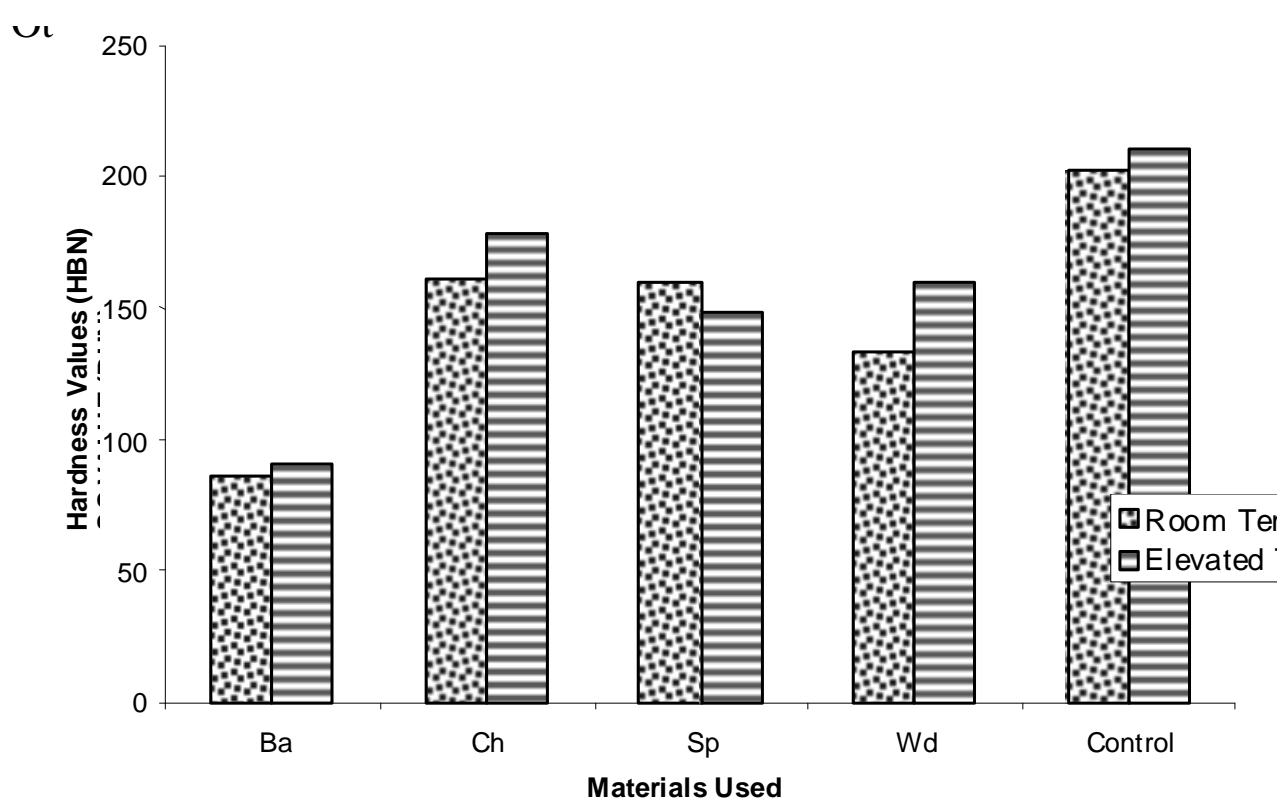

Figure 1: Bar Chart of Hardness Values of Gaskets without Fibre Mixture Mixture at Room and Elevated Temperatures 


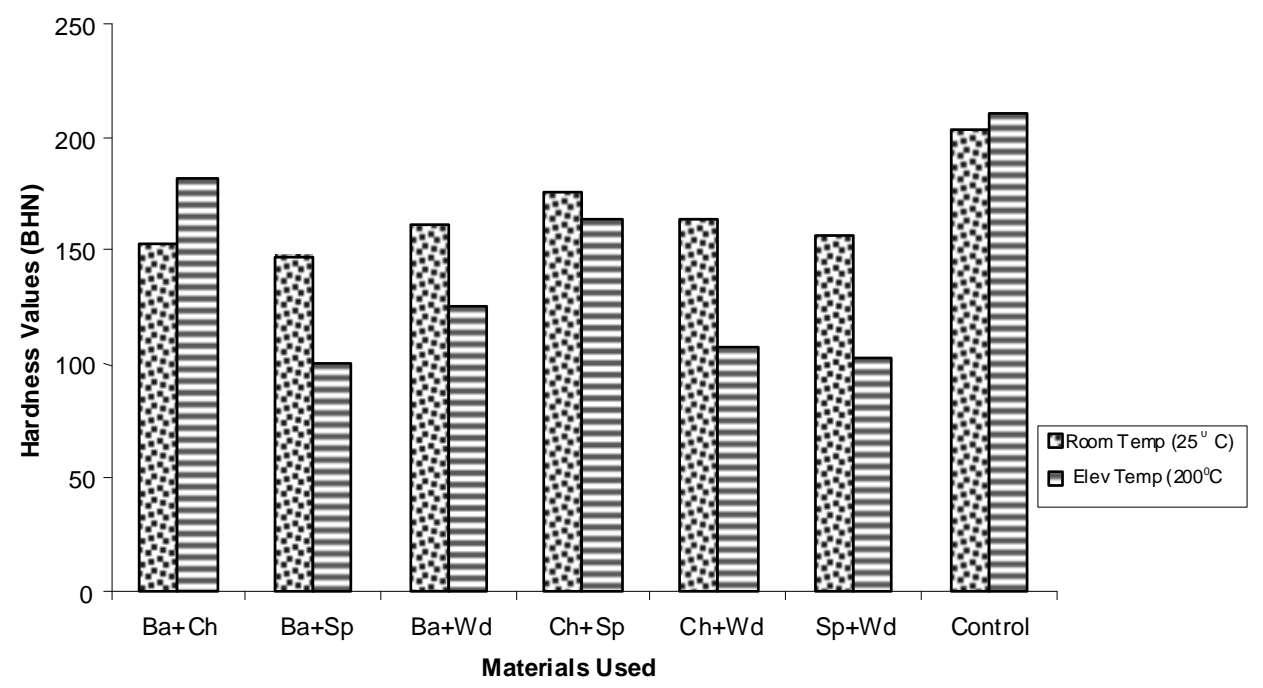

Figure 2: Bar Chart of Hardness Values for Gasket made from two Fibre Components and the Control at Room and Elevated Temperatures

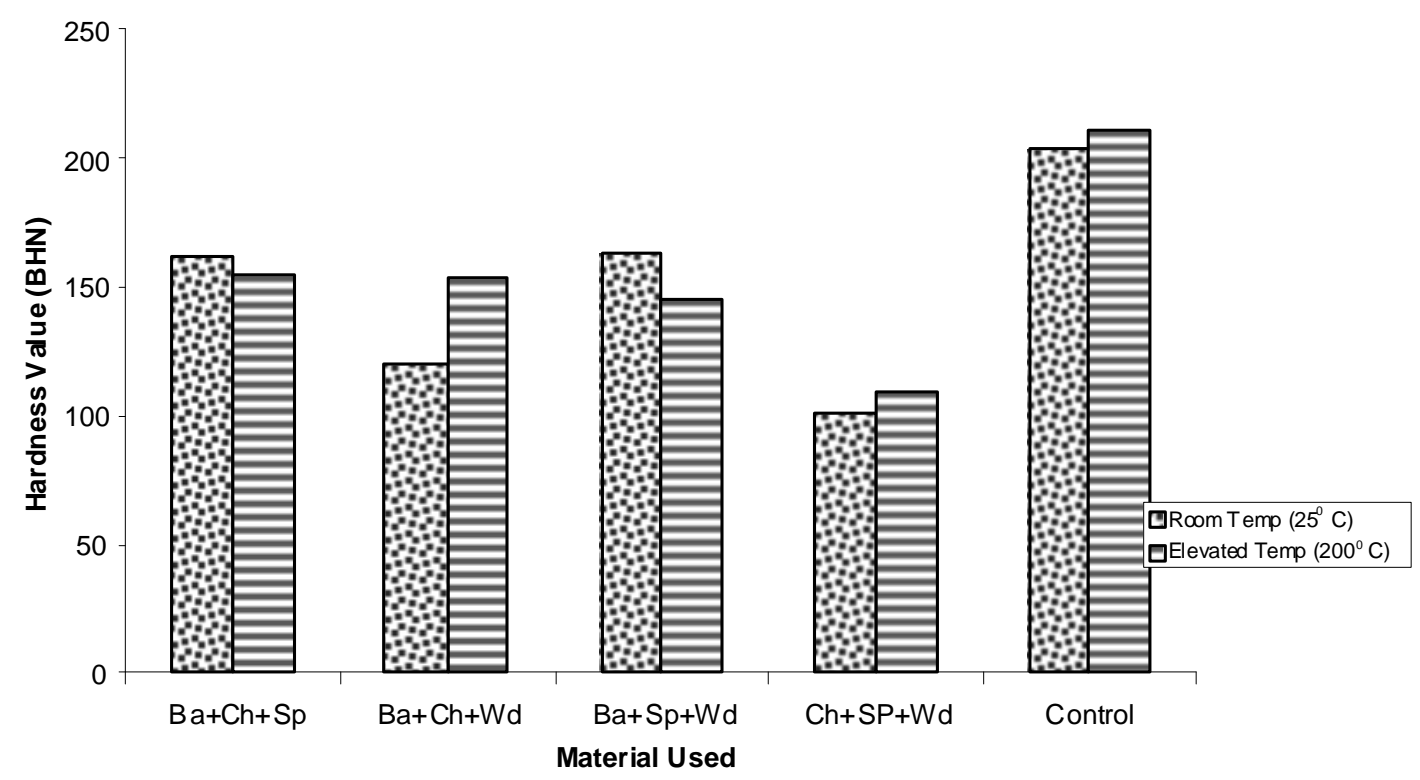

Figure 3: Bar Charts of Hardness values for Gasket made from three Fibre Components and the Control at Room and Elevated

156 Journal of Science and Technology, Vol. 28, No. 3, Dec., 2008 


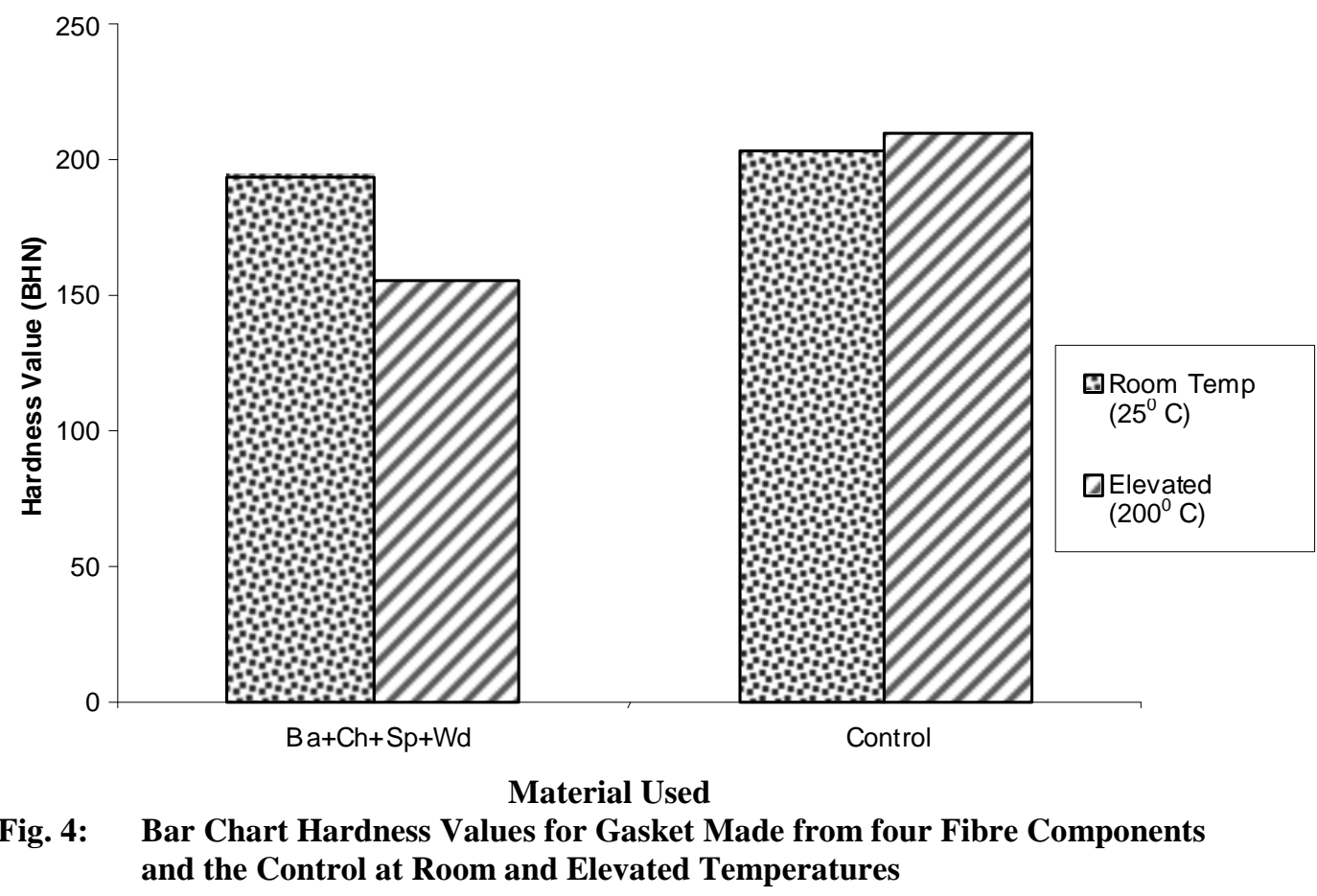

or reach a given creep rate. Rupture time depends on many factors such as creep rate, temperature and stress. Increased in any of these factors decreases the rupture time and vice versa. From figure 1, by comparing the hardness properties of each gasket produced from different fibres, it is evident that coconut husk product and the commercially sourced material has their hardness values greater than $150 \mathrm{BHN}$ at both ambient and elevated temperatures.

Figure 2 shows the response of the gasket materials produced by combining two fibres together at equal proportions to hardness at ambient and elevated temperatures. From the result, it was observed that, the commercially sourced material as well as the combination of coconut and sponge had their hardness values greater than 150BHN.

The hardness values of the combination of three fibres were shown in figure 3 . From the figure, it was observed that, product of the combination of bamboo, coconut husk and sponge together with the commercially sourced material have their values greater than $150 \mathrm{BHN}$ both at ambient and elevated temperatures. The response of the gasket material produced from the combination of all the fibres was presented in figure 4 . The hardness values at both temperatures were greater than $150 \mathrm{BHN}$.

Gasket materials are expected to have high hardness of at least $150 \mathrm{BHN}$ at both ambient and at elevated temperatures of $25^{\circ} \mathrm{C}$ and $200^{\circ} \mathrm{C}$ because of their service environment. As the engine expands and contracts during warm up and cooling periods, coupled with vibrations, the gasket material are subjected to heating. Under this condition, the material needs to maintain its properties.

\section{CONCLUSION}

The response of the produced gasket materials to both creep deformation and temperatures at ambient and at elevated values show that the com- 
bination of coconut husk and sponge, with creep rate of $0.00625 \mathrm{~mm} / \mathrm{min}$, hardness at ambient and elevated temperatures of $203 \mathrm{BHN}$ and $210 \mathrm{BHN}$ respectively, followed by the product produced from only coconut husk fibre, with creep rate of $0.02857 \mathrm{~mm} / \mathrm{min}$, hardness at ambient and elevated temperatures of $161 \mathrm{BHN}$ and $178 \mathrm{BHN}$ respectively and finally the mixture of the four fibres with creep rate of $0.03333 \mathrm{~mm} / \mathrm{min}$, hardness at ambient and elevated temperatures of $194 \mathrm{BHN}$ and 155BHN respectively can be used as a substitute for the commercially sourced gasket.

The responses of the produced gaskets to creep deformation show that the mixtures of coconut husk and sponges have the lowest creep resistance rate close to the control material. The responses of the gasket materials to hardness at room temperature show that the mixture of the four fibers: bamboo, coconut husk, sponges and wood, gave the best hardness close to the control material and therefore good for room temperature applications. The overall assessment of the compatibility and suitability tests confirmed the possible applicability of the materials as gasket in fuel pump carburetors and as well as seals in engine oil pumps. The locally produced materials have been tested and found suitable as substitute to the conventional material in this order: Coconut husk mixed with sponge $(\mathrm{Ch}+\mathrm{Sp})$ in uniform proportion; Coconut husk (Ch) alone without any mixture, and Coconut husk mixed with Wood $(\mathrm{Ch}+\mathrm{Wd})$ in uniform proportion.

\section{REFERENCES}

Adewuyi, B. O. (1999). Effect of Binders on the Mechanical Properties of Locally Produced Mineral Fibres. The Journal of Techno Science 3: 66-69.

Agarwal, B.D. and Broutman, L.J. (1990). Analysis and Performance of Fibre Composites, $2^{\text {nd }}$ ed. John Wiley and Sons. pp, 26 -28 .
Akanya, J.N. (2006). Developing Quality Standards in Nigeria. Scientific Products International. pp10.

Anderson, J. C., Leaver, K. D., Rawlings, R. D. and Alexander, J. M. (1994). Materials Science, $4^{\text {th }}$ ed., Chapman \& Hall, 2-6 Boundary Row, London SE1 8HN, UK. pp. 216235.

Brandt, R.G., Fishman, S.G. and Murday J.S. (1989). Science of Composite Interfaces, Elsevier Science Publishers. pp.7.

Chawla, K.K. (1993). Ceramic Matrix Composites, Chapman \& Hall, Boundary Raw, Lond. pp. 1.

Chris, W. (2006). Construction of Gaskets, Overview of Mechanical Seals. Wikipedia. pp. $3-4$.

Dieter, G. E (1988). Mechanical Metallurgy, McGraw-Hill Book Co-Singapore, pp. 325442.

Duffy, J. E. (1998). Modern Automotive Mechanics. The Goodheart- willcox Company, pp 93-95.

Dowling, N.E. (1993). Mechanical Behaviuor of Materials. Prentice Hall Inter. pp 1-46

Evans, M. (2003). Optimisation of manufacturing processes: a response to surface approach. Materials World 11 (5): 29-33.

Hardness Testing. (1985). "Metal Handbook", American Society for Metals, Metals park, Ohio,. $9^{\text {th }}$ ed. 8: pp. 69-113.

Hearns, E.J. (1997). "Mechanics of Materials" SM106 Creep Measurement Apparatus Manual, Tec Equipment, 2 Third Edition Butterworth Heinemann, p 462.

Martin, W.S. and Martin, T.S. (1985). "Auto Mechanics Fundamentals", The GoodheartWillcox Company, Inc. pp 48-49 